\title{
Outcomes after mechanical aortic valve replacement in children and young adults with congenital heart disease
}

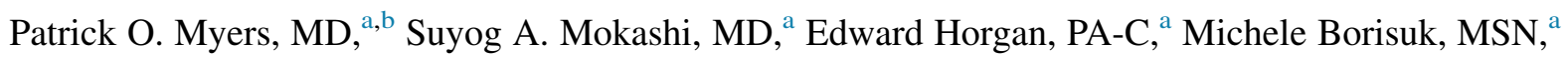

John E. Mayer, Jr, MD, ${ }^{a}$ Pedro J. del Nido, MD, ${ }^{a}$ and Christopher W. Baird, MD ${ }^{\mathrm{a}}$

\section{ABSTRACT}

Objectives: There are little recent data on the outcomes of mechanical aortic valve replacement (AVR) in children and young adults with congenital aortic valve disease. We sought to review the survival and associated thromboembolic or bleeding complications after mechanical AVR at a single center.

Methods: Data were retrospectively collected for 121 patients undergoing prosthetic AVR from 2000 to 2014. Kaplan-Meier estimates and Cox proportional hazards were employed.

Results: Median age at AVR was 16 years (interquartile range, 12-22.8 years). The valves implanted were the St Jude valve (St Jude Medical Inc, St Paul, Minn) in 79 patients (62\%), the On-X valve (On-X Life Technologies Inc, Austin, Tex) in 45 patients (35\%), and CarboMedics (Sorin SpA, Milan, Italy) in 3 patients $(2.4 \%)$. Median valve size was $23 \mathrm{~mm}$ (range, $21-25 \mathrm{~mm}$ ). There were 5 early deaths $(3.9 \%)$. Median follow-up was 5 years (range, 1.6-9.2 years; 600 patient-years). There were 14 deaths during follow-up. Survival was $90.6 \% \pm 2.8 \%$ at 1 year, $85.4 \% \pm 3.7 \%$ at 5 years, and $81.5 \% \pm 4.5 \%$ at 10 years. Freedom from aortic valve reoperation was $98 \% \pm 1.4 \%$ at 1 and 5 years, $91.5 \% \pm 3.9 \%$ at 7 years, and $78.4 \% \pm 6.9 \%$ at 10 years and at latest follow-up. Univariable analysis identified younger age, lower weight, and use of a $16-\mathrm{mm}$ CarboMedics valve as predictors of reoperation. Valve sizes of 16 or $17 \mathrm{~mm}$ have a significantly higher risk of reoperation compared with larger valves (log-rank test, $P<.001)$. At multivariable analysis, only younger age was a significant independent predictor of reoperation (hazard ratio, $0.84 ; 95 \%$ confidence interval, $0.71-0.99 ; P=.038$ ). All patients were treated with warfarin to a goal international normalized ratio of 2.0 to 3.0 . Four patients $(3.1 \% ; 0.66 \%$ per patient-year) had thromboembolic complications, and 5 patients $(3.9 \% ; 0.83 \%$ per patient-year) had bleeding events during follow-up.

Conclusions: Mechanical AVR in patients with congenital heart disease has excellent short- and midterm outcomes. Younger age was an independent predictor of reoperation. (J Thorac Cardiovasc Surg 2019;157:329-40)

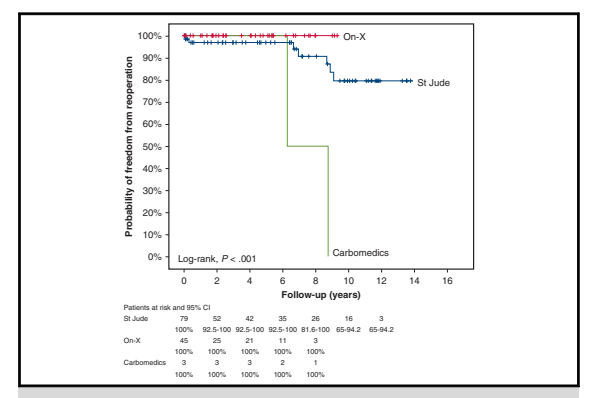

Freedom from aortic valve reoperation.

Central Message

Mechanical AVR in patients with CHD has excellent short- and midterm outcomes. Younger age is an independent predictor of reoperation.

Perspective

One hundred twenty-one patients with $\mathrm{CHD}$ underwent AVR with a mechanical prosthesis. Early and late mortality was $3.9 \%$ and $11.1 \%$. There were 9 aortic valve reoperations. The incidences of thromboembolic and bleeding complications were $0.66 \%$ and $0.83 \%$ per patient-year. Age was an independent predictor of reoperation.

See Editorial Commentary page 341.

\footnotetext{
From the a Department of Cardiac Surgery, Boston Children's Hospital and Harvard Medical School, Boston, Mass; and ${ }^{\mathrm{b}}$ Division of Cardiovascular Surgery, Geneva University Medical School, Geneva, Switzerland.

Read at the 41st Annual Meeting of The Western Thoracic Surgical Association, Whistler, British Columbia, Canada, June 24-27, 2015.

Received for publication Sept 8, 2015; revisions received April 3, 2018; accepted for publication Aug 1, 2018.

Address for reprints: Christopher W. Baird, MD, Department of Cardiac Surgery, Boston Children's Hospital and Harvard Medical School, 300 Longwood Ave, 612 Farley, Boston, MA 01225 (E-mail: bairdc1@gmail.com). 0022-5223/\$36.00

Copyright (C) 2018 Published by Elsevier Inc. on behalf of The American Association for Thoracic Surgery

https://doi.org/10.1016/j.jtcvs.2018.08.077
}

Aortic valve replacement (AVR) in children and young adults with congenital heart disease (CHD) is sometimes required, despite improvements in aortic valve reconstruction. ${ }^{1-5}$ Although the benefits and risks of mechanical valve replacement in the adult population are extensively described, there are little recent data available in patients with CHD. ${ }^{6,7}$ Controversy exists regarding the outcomes among the various surgical options and there are limited data available regarding newer prostheses. The aim of this study was to review our single-center experience with mechanical AVR in children and young adults with CHD, 


\section{Abbreviations and Acronyms}

AVR $=$ aortic valve replacement

$\mathrm{BSA}=$ body surface area

$\mathrm{CHD}=$ congenital heart disease

$\mathrm{INR}=$ international normalized ratio

identify risk factors for reoperations, and review the results of different valves.

\section{METHODS}

This was a retrospective review of all consecutive patients with CHD who underwent mechanical AVR at Boston Children's Hospital between January 2000 and January 2014. The study was approved by the institutional review board, and individual patient consent was waived. Patients were identified in the cardiac surgery and cardiology databases. The inclusion criterion was AVR during the study period with a mechanical prosthesis. Exclusion criteria were aortic valve reconstruction without valve replacement, or valve replacement with a nonmechanical valve (eg, a bioprosthetic valve, homograft, or autograft). The primary end points were reintervention on the aortic valve and mortality. Secondary end points were thromboembolic or bleeding complications.

Demographic information collected included date of birth, gender, intraoperative height, weight, and body surface area (BSA). The patient's primary diagnosis and previous interventions, including aortic valve interventions, were recorded, including aortic valve catheterization interventions, aortic valve repair or AVR, pacemaker, echocardiography, and prior procedures. Surgical data were obtained from operative notes. Variables of interest include the date of admission, date of AVR procedure, indication for AVR, date of discharge, morbidity, and any complications before discharge. In addition, the specific valve type, valve size, and valve insertion methods as well as concomitant procedures were recorded.

The following mechanical aortic valve prostheses were used: On-X (On-X Life Technologies Inc, Austin, Tex), St Jude (St Jude Medical Inc, St Paul, Minn), and 16 mm CarboMedics (Sorin SpA, Milan, Italy).

Patients were followed in our outpatient clinic at 1, 3, 6, and 12 months after surgery, and then annually, unless closer follow-up was necessary. Follow-up was documented as their latest visit in January 2014. Followup includes date of most recent follow-up and/or echocardiogram reports as part of a routine exam and any aortic valve interventions. Comorbidity, major complications, and anticoagulation data were collected from the patient records.

\section{Definitions}

The nature of the aortic valve pathology was defined as either stenosis, regurgitation, or mixed disease according to the 2014 American Heart Association/American College of Cardiology guideline for the management of patients with valvular heart disease. ${ }^{8}$ Structural valve failure was defined as development of a significant stenosis or regurgitation that was not present during the immediate postoperative period. Reintervention on the aortic valve was defined as a surgical procedure for valve re-replacement.

\section{Statistical Analysis}

Descriptive statistics used were frequency and percentage for categorical variables and mean \pm standard deviation or median (interquartile range [IQR]) when appropriate for continuous variables. The overall survival and freedom from aortic valve reintervention was calculated using KaplanMeier estimates from the conclusion of surgery to death or the latest follow-up. Differences between curves were assessed using the log-rank test. The duration of freedom from intervention was calculated from the operation to the first day when the first intervention was noted. Predictors of aortic valve reoperation were assessed by comparing the prevalence (for categorical variables) or medians (for continuous variables) of these predictors, and differences were assessed using the independent-samples Mann-Whitney $U$ statistic or Fisher exact test as appropriate. Variables with a $P$ value $\leq .1$ or deemed clinically relevant were entered into univariable and multivariable Cox proportional hazards models. All statistical tests were 2-tailed. Analyses were performed using SPSS version 23.0 for Windows (IBM-SPSS Inc, Armonk, NY).

\section{RESULTS}

\section{Patient Demographic Characteristics}

One hundred twenty-one patients were included during the study period. Patient baseline and operative characteristics are summarized in Table 1. Seventy percent of patients were male, and the median age at operation was 16.3 years (IQR, 12-22.8 years). 74 patients $(58.3 \%)$ were younger than age 18 years. A majority of patients $(n=80 ; 63 \%)$ had undergone at least 1 prior aortic valve operation, although a majority still had their native aortic valve $(\mathrm{n}=105 ; 82.7 \%)$. The fundamental diagnosis was predominantly congenital aortic stenosis and borderline hypoplastic left heart syndrome or Shone's complex $(\mathrm{n}=64 ; 50.3 \%)$, followed by conotruncal anomalies $(\mathrm{n}=24 ; 18.9 \%)$. Of note, 8 patients $(6.3 \%)$ had single ventricle physiology at different stages (eg, Glenn or Fontan), and 7 patients $(5.5 \%)$ had undergone a previous arterial switch operation and required replacement of their neoaortic valve. Aortic regurgitation $(\mathrm{n}=53 ; 41.7 \%)$ or mixed aortic disease $(\mathrm{n}=53 ; 41.7 \%)$ were the most frequent indications for operation. One patient had recurrent embolic events with a StarrEdwards ball-valve prosthesis without evidence of stenosis or regurgitation, and was referred for reoperation due to suspected recurrent thrombosis and embolism from this valve.

\section{Operative Characteristics}

Operative characteristics are detailed in Table 2. The valve types used were St Jude in 79 patients (62\%), On-X in 45 patients $(35 \%)$, and CarboMedics in 3 patients $(2.4 \%)$. The On-X valves were implanted from 2004 or later, whereas St Jude valves were implanted throughout the study period. The median valve size was $23 \mathrm{~mm}$ (IQR, 21-25 mm). The most commonly used sizes for St Jude valves were $21 \mathrm{~mm}(23.8 \%)$ and $23 \mathrm{~mm}(23.8 \%)$, On-X valves were $21 \mathrm{~mm}(31.1 \%)$ and $23 \mathrm{~mm}(26.7 \%)$ and all 3 patients who received CarboMedics valves had $16 \mathrm{~mm}$ valves implanted $(P=.001)$. Patients who received a CarboMedics valve were younger (median age, 4.6 years; IQR, 3.4-4.6 years) than those who received On-X (median, 18.7 years; IQR, 14.4-24.0 years) and St Jude valves (median, 15.7 years; IQR, 11.7-21.8 years).

Concomitant operations were frequent and are listed in Table 2. Forty-two patients $(33 \%)$ required aortic root enlargement: 25 patients $(20 \%)$ using a Konno procedure 
TABLE 1. Baseline characteristics

\begin{tabular}{|c|c|}
\hline Characteristic & $\begin{array}{c}\text { Overall } \\
\text { population }\end{array}$ \\
\hline \multicolumn{2}{|l|}{ Patients } \\
\hline Number & 121 \\
\hline Male & $90(70.9)$ \\
\hline Weight (kg) & $59.0(34.3-72.1)$ \\
\hline \multicolumn{2}{|l|}{ Native aortic valve anatomy } \\
\hline Unicuspid & $7(5.5)$ \\
\hline Bicuspid & 44 (34.6) \\
\hline Tricuspid & $65(54)$ \\
\hline Quadricuspid & $5(3.9)$ \\
\hline \multicolumn{2}{|l|}{ Underlying diagnosis } \\
\hline Congenital aortic stenosis & $51(42)$ \\
\hline Conotruncal anomalies & $22(18)$ \\
\hline Shone's complex & $6(5)$ \\
\hline Other congenital & $10(8.3)$ \\
\hline Connective tissue disorder & $12(9.9)$ \\
\hline $\begin{array}{l}\text { Subacute bacterial endocarditis-acute } \\
\text { rheumatic fever }\end{array}$ & $6(5)$ \\
\hline Atrioventricular canal & $6(5)$ \\
\hline Single ventricle & $8(6.6)$ \\
\hline \multicolumn{2}{|l|}{ Operative } \\
\hline Valve implants & 127 \\
\hline Age (y) & $16.3(12.0-22.8)$ \\
\hline $1-6$ & $6(4.7)$ \\
\hline $6-12$ & $26(20.5)$ \\
\hline $12.1-18$ & $42(33.1)$ \\
\hline$>18$ & $53(41.7)$ \\
\hline \multicolumn{2}{|l|}{ Nature of aortic valve lesion } \\
\hline Stenosis & $7(5.5)$ \\
\hline Regurgitation & $49(39)$ \\
\hline Mixed aortic valve disease & $47(37)$ \\
\hline Prosthetic aortic valve disease & $21(17)$ \\
\hline Other & $3(2.4)$ \\
\hline Prior aortic valve surgery & $80(63)$ \\
\hline 1 & $50(39.4)$ \\
\hline 2 & $26(20.5)$ \\
\hline 3 & $4(3.1)$ \\
\hline \multicolumn{2}{|l|}{ Aortic valve at replacement } \\
\hline Native & $93(73)$ \\
\hline Mechanical prosthesis & $19(15)$ \\
\hline Homograft & $4(3.1)$ \\
\hline Biological prosthesis & $3(2.4)$ \\
\hline Ross procedure & $2(1.6)$ \\
\hline Neoaortic valve after arterial switch & $6(4.7)$ \\
\hline Single ventricle physiology & $8(6.3)$ \\
\hline
\end{tabular}

Values are presented as $n, n(\%)$, or median (interquartile range).

and 17 patients $(13 \%)$ using another type of annulus enlarging procedure. These procedures were used in 6 young children (aged 1-6 years; 14\%), 10 preadolescent children (aged 6-12 years; 24\%), 12 adolescents (aged $12-18$ years; $29 \%)$, and 14 adults (33\%; Fisher exact test
TABLE 2. Operative data

\begin{tabular}{lc}
\hline \multicolumn{1}{c}{ Operative variable } & Value \\
\hline Mechanical valve implanted* & \\
St Jude & $79(62.2)$ \\
On-X & $45(35.4)$ \\
CarboMedics & $3(2.4)$ \\
Valve size (mm) & $23(21-25)$ \\
St Jude & $21(17-31)$ \\
On-X & $23(19-29)$ \\
CarboMedics & 16 \\
Associated procedures & \\
Aortic root enlargement & $42(33)$ \\
Konno $\dagger$ & $25(20)$ \\
Nicks & $6(4.7)$ \\
Manougian & $6(4.7)$ \\
Other & $5(4)$ \\
Ascending aortic procedures & \\
Aortic root replacement (Bentall) & $18(14)$ \\
Ascending aorta replacement & $3(2.4)$ \\
Ascending aorta or root patch enlargement & $30(24)$ \\
Reduction aortoplasty & $5(4)$ \\
Other associated procedures & \\
Mitral valve replacement & $14(11)$ \\
Mitral valvuloplasty & $8(6.3)$ \\
ASD repair & $7(6)$ \\
Tricuspid valve repair & $2(1.6)$ \\
PPM or AICD placement, revision & $7(5.5)$ \\
Subaortic stenosis resection & $8(6.3)$ \\
Endocardial fibroelastosis resection & $1(0.8)$ \\
RV-PA conduit, RVOT enlargement, PA plasty & $12(9.4)$ \\
Maze & $4(3)$ \\
Coronary procedure (CABG, intramural unroofing) & $2(1.6)$ \\
Residual VSD repair & $2(1.6)$ \\
Fontan conversion or revision & $2(1.6)$ \\
LVOT aneurysm repair & $1(0.8)$ \\
\hline
\end{tabular}

Values are presented as $\mathrm{n}(\%)$ or medial (interquartile range). $A S D$, Atrial septa defect; $P P M$, permanent pacemaker; $A I C D$, automatic implantable cardioverterdefibrillator; $R V$, right ventricular; $P A$, pulmonary artery; $R V O T$, right ventricular outflow tract; $C A B G$, coronary artery bypass grafting; $V S D$, ventricular septal defect, $L V O T$, left ventricular outflow tract. *St Jude; St Jude Medical Inc, St Paul, Minn; OnX; On-X Life Technologies Inc, Austin, Tex; CarboMedics; Sorin SpA, Milan, Italy. $\dagger$ Four of these patients also had an additional root enlargement procedure.

assessing distribution between age groups $P=.57)$. Eighteen patients $(14 \%)$ underwent an aortic root replacement with a Bentall procedure.

\section{Early Outcomes}

There were 7 early deaths $(5.5 \%), 2$ due to neurologic injury, 2 due to left ventricle failure, 1 due to sepsis, 1 due to tamponade, and 1 due to coronary ischemia. Use of an aortic root enlargement procedure did not significantly increase early mortality, with 2 deaths in patients with root enlargement ( 2 out of $42 ; 5 \%$ ), compared with 5 deaths without enlargement (5 out of $85 ; 5.8 \%$; $P=.60)$. Perioperative complications included 
unplanned reoperation in $10(7.9 \%)$, of which 6 were reexplorations for bleeding $(4.7 \%)$, pacemaker placement in $6(4.7 \%)$, and paravalvular leak in 7 patients $(5.5 \%)$. Of these 7 patients with paravalvular leaks, 5 required no reintervention, 1 died acutely from cardiac tamponade, and 1 required redo AVR 7 years later due to prosthethic valve failure.

\section{Follow-up}

Eight patients were lost to follow-up following discharge and were excluded from further analysis. The median follow-up was 4.8 years (IQR, 0.6-8 years; 581 patientyears), and was 6.1 years for patients with a St Jude valve, 3.9 years with an On-X valve, and 8.6 years with a CarboMedics valve. There were 10 late deaths and survival was $91.4 \% \pm 2.6 \%$ at 1 year, $83.8 \% \pm 3.8 \%$ at 5 years, and $81.5 \% \pm 4.4 \%$ at 10 years (Figure 1). Five patients died from unknown causes, and 1 patient died from each of the following causes: mechanical mitral valve failure at 1.2 years, autoimmune disease at 3 years, following heart transplant at 5 years, redo AVR at 7.5 years, and sepsis at 10 years.

Nine patients $(7.5 \%)$ underwent reoperation to replace the prosthetic aortic valve, 7 having had a St Jude valve $(8.8 \%), 2$ with a $16 \mathrm{~mm}$ CarboMedics valve $(66 \%)$, and none with an On-X valve (Table 3). Reoperations occurred at a median of 7.1 years (IQR, 3-8.9 years) after AVR, and the intervals were similar for St Jude and CarboMedics valves ( 7.1 vs 7.3 years, respectively). Six patients had aortic stenosis primarily due to pannus formation that resulted in a median mean gradient of $50 \mathrm{~mm} \mathrm{Hg}$ and left ventricular end diastolic pressure of $22 \mathrm{~mm} \mathrm{Hg}$. There were 3 patients in whom thrombus formation was present; 1 patient had acute thrombosis of the valve due to inadequate warfarin levels that resulted in severe aortic stenosis, 1 patient receiving extracorporeal membrane oxygenation had acute valve thrombosis likely related to poor flow across the aortic valve and inadequate anticoagulation, and 1 patient had the valve explanted and replaced for unexplained thrombotic events. An additional patient had the valve removed from presumed endocarditis and a significant paravalvular leak.

As shown in Figure 2, freedom from aortic valve reoperation was $98 \% \pm 1.3 \%$ at 1 and 5 years, $91.4 \% \pm 3.9 \%$ at 7 years, and $78.3 \% \pm 6.9 \%$ at 10 years and at latest followup. Freedom from aortic valve reoperation was significantly better with the On-X valve $(P<.001)$. As shown in Figure 3, smaller sized valves ( 16 to $17 \mathrm{~mm}$ ) have significantly higher risk of reoperation compared with larger sized valves (19 to $27 \mathrm{~mm}$ ) (Log-rank test $P<.001$ ).

Univariable predictors of reoperation are detailed in Table 4. Younger age, lower weight, a diagnosis of subacute bacterial endocarditis or acute rheumatic fever, and use of a 16-mm CarboMedics valve were all significantly associated with aortic valve reoperation. Time-dependent predictors of reoperation are detailed in Table 5. At univariable analysis, younger age (hazard ratio [HR], 0.8 for each increase in year; $P=.002)$ and in particular children aged 1 to 6 years (HR, 28.9; $P=.005$ ), lower weight (HR, 0.96 for each increase in $1 \mathrm{~kg} ; P=.04)$, and the valve type $(P=.028)$ were predictors of reoperation. At multivariable Cox proportional hazards analysis, only age was an independent predictor of reoperation ( $\mathrm{HR}, 0.84 ; 95 \%$ confidence interval, 0.71-0.99; $P=.038$ ).

Five patients experienced early perioperative bleeding events. Four patients $(0.66 \%$ per patient-year $)$ presented thromboembolic complications (3 strokes), and 5 patients $(0.83 \%$ per patient-year) experienced bleeding events during follow-up.

There were no late bleeding events. All patients were treated with warfarin (goal international normalized ratio [INR], 2.0-3.0). Forty-two patients also received aspirin $(33.1 \%)$, and 1 received clopidogrel $(0.8 \%)$. One poorly compliant patient presented with "seizure-like activity" but workup was negative. One patient developed prosthetic valve endocarditis that required reoperation.

The interaction between implant size and BSA was investigated using both indexed valve size (implanted valve size divided by BSA), and an estimated implanted aortic valve $z$ score, calculated using the rated valve size compared with BSA, as reported previously in the mitral position. ${ }^{9}$ The median indexed valve size was larger in patients who required a reoperation: $21.5 \mathrm{~mm} / \mathrm{m}^{2}$ (range, $11.5-42 \mathrm{~mm} / \mathrm{m}^{2}$ ) compared with $14.5 \mathrm{~mm} / \mathrm{m}^{2}$ (range, $8.3-32.8 \mathrm{~mm} / \mathrm{m}^{2}$ ) in patients who did not require a reoperation $(P=.01)$. The same interaction was found regarding median estimated $z$ score, which was larger in patients who required a reoperation: 1.33 (range, 0.89- 4.46) compared with 0.99 (range, -1.32 to $4.24 ; P=.04$ ) in patients who did not require a reoperation. Stratifying these $z$ score or indexed valve size by quartiles, reoperations occurred slightly more frequently in the highest $z$ score or indexed valve size quartile $(16.1 \%$ in the highest quartile, with an indexed valve size $>18.8 \mathrm{~mm} / \mathrm{m}^{2}$ vs $4.2 \%$ for the lower quartiles with an indexed valve size $<18.8 \mathrm{~mm} / \mathrm{m}^{2}$ ), although not to a significant level $(P=.24)$. The difference was not significant in median estimated $z$ score in terms of mortality $(P=.16$ and $P=.45$ for the difference between median indexed valve size and estimated $z$ score in survivors vs nonsurvivors, respectively). Oversizing thus appears to increase the risk of reoperation, but not mortality.

\section{DISCUSSION}

Aortic valve disease is among the most common congenital cardiac defects, occurring in up to $5 \%$ of all children with heart disease. ${ }^{10}$ When feasible, aortic valve reconstruction is currently preferred over valve replacement. 

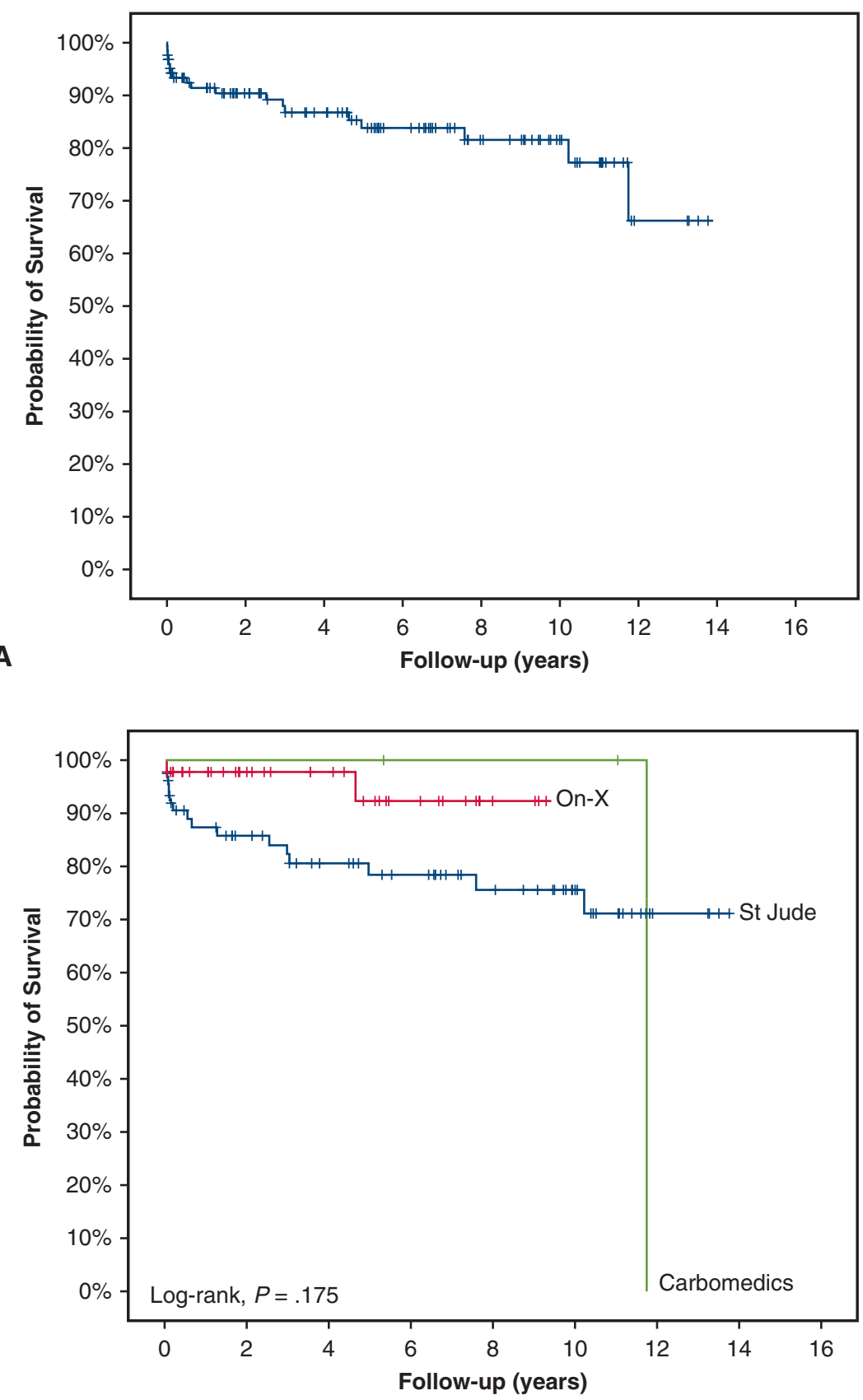

$$
\begin{array}{lccccccc}
\text { Patients at risk and } 95 \% \mathrm{Cl} & & & & & \\
\text { St Jude } & 79 & 52 & 42 & 35 & 27 & 18 & 4 \\
& 100 \% & 77.8-94.2 & 70.9-90.5 & 68.2-89 & 64.4-87.2 & 64.4-87.2 & 57.5-85.1 \\
\text { On-X } & 45 & 25 & 21 & 11 & 3 & & \\
& 100 \% & 93.4-100 & 93.4-100 & 80.9-100 & 80.9-100 & & \\
\text { Carbomedics } & 3 & 3 & 3 & 2 & 2 & 1 \\
& 100 \% & 100 \% & 100 \% & 100 \% & 100 \% & 100 \%
\end{array}
$$

FIGURE 1. Kaplan-Meier estimates of survival. A, Unstratified. B, Stratified by valve type. The median follow-up was 5 years (interquartile range, 1.6-9.2 years; 600.2 patient-years), specifically 6.1 years for patients with a St Jude valve (St Jude Medical Inc, St Paul, Minn), 3.9 years with an On-X valve (On-X Life Technologies Inc, Austin, Tex), and 8.6 years with a CarboMedics valve (Sorin, SpA, Milan, Italy). CI, Confidence interval. 
TABLE 3. Patients requiring aortic valve reoperation

\begin{tabular}{|c|c|c|c|c|c|}
\hline Patient & Fundamental diagnosis & Valve type* & Valve size & $\begin{array}{c}\text { Reason for aortic valve replacement } \\
\text { reoperation }\end{array}$ & $\begin{array}{c}\text { Time from initial to } \\
\text { aortic valve } \\
\text { replacement } \\
\text { reoperation }(y)\end{array}$ \\
\hline 1 & Endocarditis & CarboMedics & 16 & Aortic stenosis/fibrosis (pannus formation) & 6.3 \\
\hline 2 & Interrupted aortic arch & CarboMedics & 16 & Aortic stenosis/fibrosis (pannus formation) & 8.7 \\
\hline 3 & Endocarditis & St Jude & 17 & Endocarditis, paravalvular leak & 0.3 \\
\hline 4 & Congenital aortic stenosis & St Jude & 17 & Aortic stenosis/fibrosis (pannus formation) & 6.7 \\
\hline 5 & $\begin{array}{l}\text { Transposition, double-outlet right } \\
\text { ventricle, ventricular septal defect }\end{array}$ & St Jude & 19 & Aortic stenosis/fibrosis (pannus formation) & 7.0 \\
\hline 6 & Marfan syndrome & St Jude & 21 & Aortic stenosis/fibrosis (pannus formation) & 8.6 \\
\hline 7 & Truncus arteriosus & St Jude & 23 & Aortic stenosis/fibrosis (pannus formation) & 9.1 \\
\hline 8 & Interrupted aortic arch & St Jude & 23 & Thrombus & 1.0 \\
\hline 9 & Congenital aortic stenosis & St Jude & 25 & Thrombus & 8.9 \\
\hline
\end{tabular}

*CarboMedics; Sorin SpA, Milan, Italy; St Jude; St Jude Medical Inc, St Paul, Minn.

However, valve repair may not always be possible and replacement becomes necessary. Replacement in children and young adults poses a difficult problem given the smaller patient size and limited valve choices. ${ }^{6,11,12}$ Homograft and bioprosthetic valves continue to have high rates of degeneration in pediatric populations. ${ }^{13,14}$ The Ross procedure provides excellent hemodynamic results, superior longevity, freedom from anticoagulation, and a decreased susceptibility to endocarditis. ${ }^{15,16}$ However, the pulmonary valve is not always suitable for translocation into the aortic position. Some examples include after a repair of truncus arteriosus or tetralogy of Fallot, or in patients with connective tissue disorders. The Ross procedure remains a technically demanding procedure, which is associated with a low, but measurable, rate of autograft failure or reoperations on the right ventricle to pulmonary artery conduit. Despite the drawbacks of potential thromboembolic complications and lifelong anticoagulation, mechanical AVR has been recommended ${ }^{8}$ and is routinely performed in children and young people. Structural valve deterioration is essentially nonexistent, although there is the cost of lifelong anticoagulation and potential for pannus ingrowth or endocarditis. Overall, reports suggest mechanical AVR is a safe and durable option in children, ${ }^{11,12,17,18}$ and newer prostheses and longer follow-up are now available.

The current study assessed reoperations, thromboembolic or bleeding complications, endocarditis, and deaths following mechanical AVR in patients with CHD who were treated at Boston Children's Hospital between 2000 and 2014. The study population was relatively heterogeneous, spanning the breadth of CHD, including patients after single ventricle palliation, neoaortic valve disease after arterial switch, and truncus arteriosus repair. These patients had a median age of 16 years, with only one-quarter of patients younger than age 12 years. There were no infants or newborn infants. These operations were complex procedures, with $63 \%$ of patients having had a prior aortic valve procedure, and almost one-quarter having had 2 or 3 prior aortic valve procedures. The AVR procedure required aortic root replacement or enlargement in $35 \%$ of patients, and a concomitant additional cardiac procedure in the majority of patients. Survival was $81 \%$ at 10 years, and freedom from aortic valve reoperation was $78 \%$ at 10 years. Most late deaths were due to the underlying CHD; that is, from issues with other valves (eg, mechanical mitral valve dysfunction) or with transplantation for end-stage disease. It is worthy of note that most patients were not undergoing reoperation for structural valve deterioration - the majority were for pannus formation $(66 \%)$. This may help explain why patients with an On-X valve had fewer reoperations, because the leaflet housing of this device is higher and may limit or delay the pannus ingrowth. We found that indicators of smaller children (ie, younger age, lower weight, and the use of a $16 \mathrm{~mm}$ CarboMedics valve) were predictors of reoperation. Multivariable analyses only found young age as an independent predictor of reoperation. All of these univariable predictors most likely interacted and were different indicators that the group of small children was at higher risk of reoperation. It is not surprising that the multivariable analyses did not identify any of these other factors as independent predictors of reoperation.

Associated procedures, such as aortic root enlargement or replacement, were not significant predictors of reoperation. There was a trend for increased rate of reoperation in patients with aortic root enlargement $(12.5 \%$ vs $5.3 \%$ reoperation rate without enlargement; $P=.23$ ), particularly Konno aortic root enlargement $(13.6 \% ; P=.22)$, and MVR (15.4\% vs $6.1 \%$ reoperation rate without mitral valve replacement; $P=.23$ ) or subaortic stenosis resection 

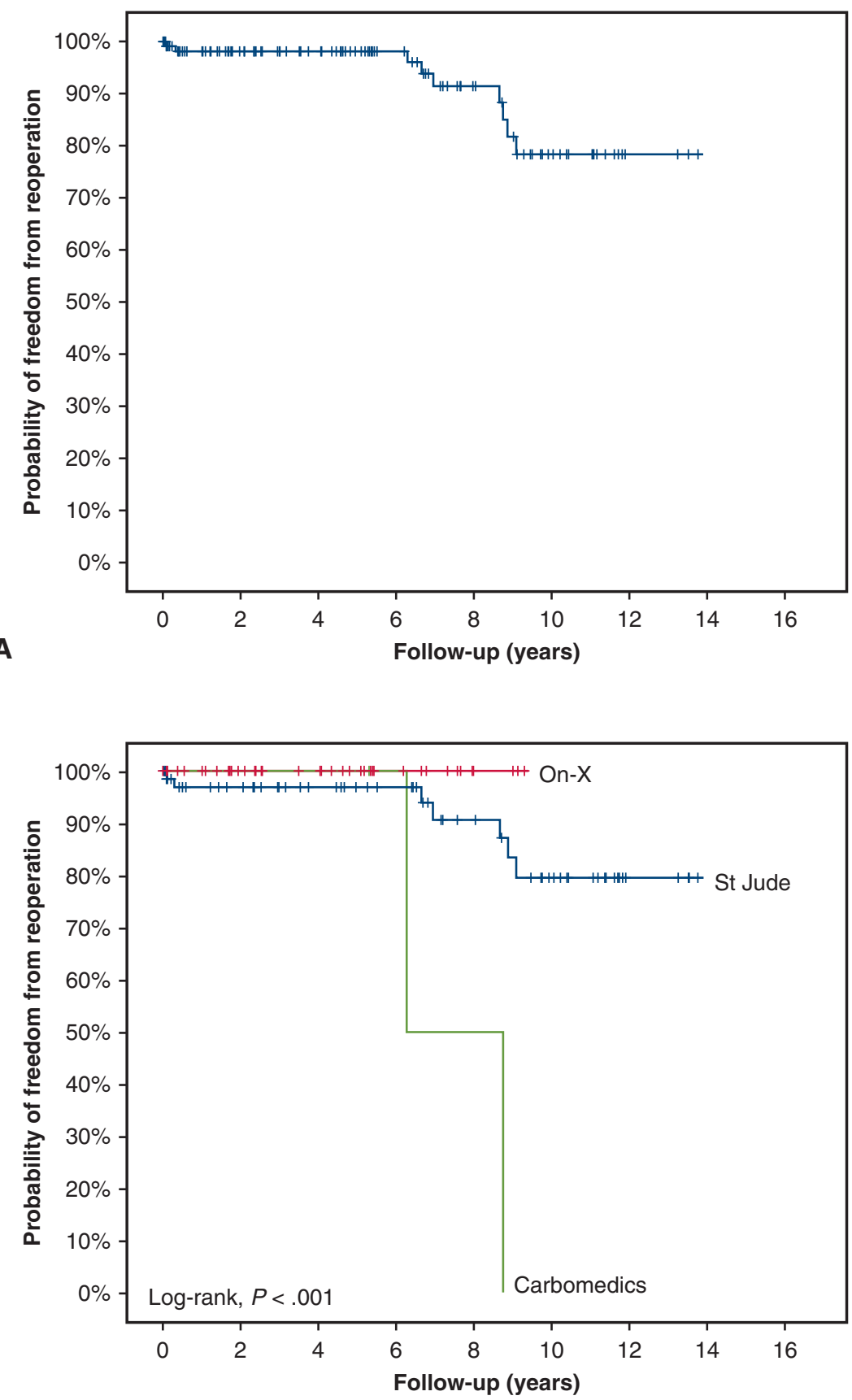

Patients at risk and $95 \% \mathrm{Cl}$

$\begin{array}{lccccccc}\text { St Jude } & 79 & 52 & 42 & 35 & 26 & 16 & 3 \\ & 100 \% & 92.5-100 & 92.5-100 & 92.5-100 & 81.6-100 & 65-94.2 & 65-94.2 \\ \text { On-X } & 45 & 25 & 21 & 11 & 3 & & \\ & 100 \% & 100 \% & 100 \% & 100 \% & 100 \% & & \\ \text { Carbomedics } & 3 & 3 & 3 & 2 & 1 & & \\ \text { B } & 100 \% & 100 \% & 100 \% & 100 \% & 100 \% & & \end{array}$

FIGURE 2. Freedom from reoperation. A, Freedom from aortic valve reoperation was $98 \% \pm 1.3 \%$ at 1 and 5 years, $91.4 \% \pm 3.9 \%$ at 7 years, and $78.3 \% \pm 6.9 \%$ at 10 years to latest follow-up. B, Freedom from aortic valve reoperation was significantly better with the On-X valve (On-X Life Technologies Inc, Austin, Tex $)(P<.001)$. $C I$, Confidence interval. 


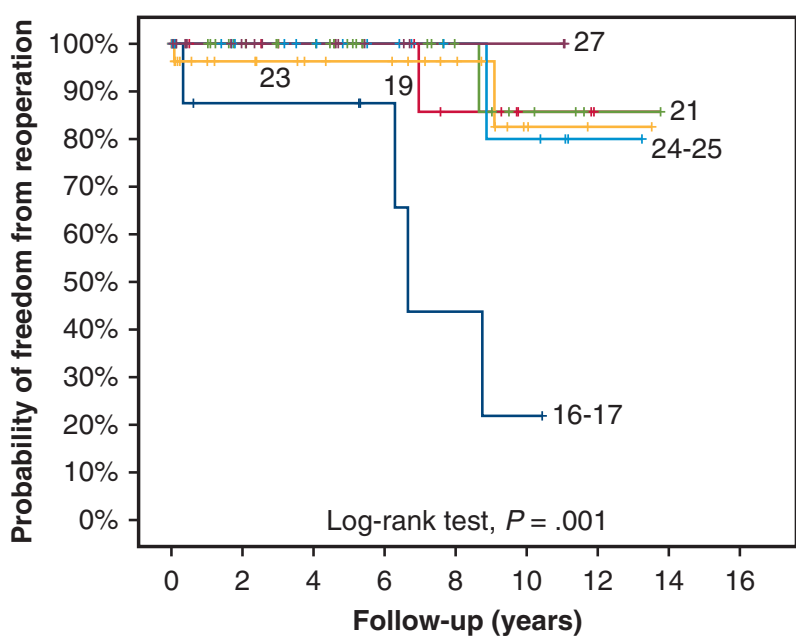

FIGURE 3. Freedom from reoperation stratified by valve size. Valve sizes of 16 to $17 \mathrm{~mm}$ had a significantly higher risk of reoperation compared to larger valves of 19 to $27 \mathrm{~mm}$.

$(33.3 \%$ vs $5.8 \%$ reoperation rate without resection; $P=.06$ ), although this did not reach statistical significance.

Placement of a prosthesis that is as large as technically possible seems to be desirable at the time of AVR because the prosthesis will not grow with the child and may lead to patient-prosthesis mismatch with somatic growth. This often requires aortic root enlargement in smaller children. The Manouguian ${ }^{19}$ and Konno ${ }^{20}$ procedures are reported to enable placement of a prosthesis 2 sizes larger than valve replacement without root enlargement, whereas the Nicks procedure, ${ }^{21}$ with a more limited enlargement, is reported to enable placement of a prosthesis 1 size larger. ${ }^{22}$ Although our study population includes older patients with congenital aortic valve disease, as well as patients with conotruncal anomalies (such as truncus arteriosus) that are associated with a larger aortic annulus than within the normal population, $29 \%$ of patients did require an aortic root enlargement, with a mix of techniques used. The distribution of aortic root enlargement was relatively uniform between the age groups $(P=.60)$, yet slightly more prevalent in older patients. This finding is likely due to the heterogeneous patient population, which included patients with aortic stenosis and a small aortic annulus and root who were referred at an older age. Aortic root enlargement was not associated with increased early or late mortality or reoperations on the aortic valve. This is consistent with reported data on aortic root enlargement both in pediatric and adult populations. ${ }^{22}$

Other than procedures on the aorta, the most frequent associated procedure was to address the mitral valve in 22 patients $(17.3 \%)$, with a mitral valve replacement in 14 patients and repair in 8 patients. Mitral valve replacement was associated with a trend toward increased late aortic valve reoperations $(15.4 \%$ vs $6.1 \%$ without mitral valve replacement; $P=.23$ ). There are relatively few reports on aortic and mitral valve procedures in children available. Alsoufi and colleagues ${ }^{7}$ reported the outcomes of double valve replacement in 84 children, with an early mortality of $4 \%$, $78 \% 15$-year survival, and 59\% freedom from reoperation at 15 years. The majority of patients $(94 \%)$ had rheumatic heart disease. ${ }^{7}$ Although they did not include a direct control group of single aortic valve replacement, the authors concluded that although the risk of reoperation was increased, operative risk and freedom from other valverelated complications were comparable to patients with single valve replacement. ${ }^{7}$ Given the limited sample size, our findings unfortunately cannot provide more information regarding this point, although the data seem to indicate that patients with concomitant mitral valve procedures were among a group at higher risk for reoperation during long-term follow-up.

A major drawback of mechanical prostheses is the need for anticoagulation. Current guidelines include a class I recommendation for warfarin to achieve an INR of 2.0 to 3.0 after AVR with a mechanical prosthesis without risk factors for thrombosis. ${ }^{8}$ The addition of aspirin decreases the risk of thromboembolism, with a slight increase in the risk of bleeding. ${ }^{23}$ Thromboembolism has been reported to occur in $0 \%$ to $0.3 \%$ per patient-year in children, slightly lower than in adults $(1.5 \%-2 \%)$, whereas bleeding occurs in $0 \%$ to $0.3 \%$ per patient-year (compared with $3 \%$ in adults). ${ }^{24}$ Anticoagulation in this study comprised warfarin with a goal INR of 2.0 to 3.0 in all patients, with the addition of aspirin in $33 \%$ and clopidogrel in 1 patient at the discretion of the referring cardiologist and surgeon. The linearized rates of thrombo-embolism $(0.66 \%$ per patient-year) and bleeding $(0.83 \%$ per patient-year) were slightly higher than those described previously in children, although significantly lower than those reported in adult patients.

Novel prosthetic valves are regularly being introduced; however, there are very few reports that detail the earlyand midterm outcomes in patients with CHD using these newer prostheses. Valve design has a significant influence on thrombogenicity and the need for anticoagulation. There are currently four Food and Drug Administration-approved bileaflet mechanical prostheses for use in the aortic position: St Jude Medical, CarboMedics, On-X, and Medtronic Open Pivot valve (Medtronic ATS Medical Inc, Minneapolis, Minn). ${ }^{25}$ All of these mechanical valves have been shown to have excellent and comparable hemodynamic performance both in vitro and in clinical studies. The CarboMedics valve is available in smaller sizes, which allows placement in smaller children and was the only prosthetic valve available in a $16 \mathrm{~mm}$ size in the current experience. Although the CarboMedics valves (and smaller children) had worse outcomes in this report, it should be noted that this finding was based on only 3 implants, and it is noteworthy that these 3 patients were reoperation-free up to 
TABLE 4. Univariable predictors of reoperation

\begin{tabular}{|c|c|c|c|}
\hline Clinical characteristic & Without a reoperation & Reoperation & $P$ value \\
\hline Patients & $118(92.9)$ & $9(7.1)$ & - \\
\hline Age (y) & $18.6(4.5$ to 48.1$)$ & 13.7 (9.6 to 22.8$)$ & .001 \\
\hline $1-6$ & $3(50)$ & $3(50)$ & \\
\hline $6-12$ & $23(88.5)$ & $3(11.5)$ & \\
\hline $12-18$ & $40(95.2)$ & $2(4.8)$ & \\
\hline$>18$ & $52(98.1)$ & $1(1.9)$ & \\
\hline Weight $(\mathrm{kg})$ & $60(8$ to 121$)$ & $64.9(25$ to 91$)$ & .018 \\
\hline $\operatorname{BSA}\left(\mathrm{m}^{2}\right)$ & 1.67 (0.53 to 2.47$)$ & $1.70(0.94$ to 2.0$)$ & $>.99$ \\
\hline Fundamental diagnosis & & & .03 \\
\hline Congenital AS & $48(96)$ & $2(4)$ & \\
\hline Borderline HLHS, Shone's complex & $14(100)$ & $0(0)$ & \\
\hline Conotruncal anomalies & $20(83.3)$ & $4(16.7)$ & \\
\hline Other congenital & $21(100)$ & $0(0)$ & \\
\hline Connective tissue disorder & $11(91.7)$ & $1(8.3)$ & \\
\hline SBE-ARF & $4(66.7)$ & $2(33.3)$ & \\
\hline Aortic valve disease & & & .32 \\
\hline Stenosis & $20(100)$ & $0(0)$ & \\
\hline Regurgitation & $50(94.3)$ & $3(5.7)$ & \\
\hline Mixed disease & $47(88.7)$ & $6(11.3)$ & \\
\hline Native valve anatomy & & & .45 \\
\hline Unicuspid & $7(100)$ & $0(0)$ & \\
\hline Bicuspid & $42(95.5)$ & $2(4.5)$ & \\
\hline Tricuspid & $64(92.8)$ & $5(7.2)$ & \\
\hline Quadricuspid & $4(80)$ & $1(20)$ & \\
\hline No. of prior aortic valve procedures & & & .27 \\
\hline 0 & $46(97.9)$ & $1(2.1)$ & \\
\hline 1 & $44(88)$ & $6(12)$ & \\
\hline 2 & $24(92.3)$ & $2(7.7)$ & \\
\hline 3 & $4(100)$ & $0(0)$ & \\
\hline CPB time (min) & $164(60$ to 386$)$ & $171(137$ to 333$)$ & .63 \\
\hline Aortic crossclamp time (min) & 105 (42 to 259$)$ & 113 (97 to 174$)$ & .97 \\
\hline Valve type* & & & .001 \\
\hline St Jude & $72(91.1)$ & $7(8.9)$ & \\
\hline On-X & $45(100)$ & $0(0)$ & \\
\hline CarboMedics & $1(33.3)$ & $2(66.6)$ & \\
\hline Valve size $(\mathrm{mm})$ & $23(16$ to 31$)$ & $23(17$ to 25$)$ & .018 \\
\hline Valve size & & & .014 \\
\hline $16-17$ & $6(60)$ & $4(40)$ & \\
\hline 19 & $15(93.8)$ & $1(6.3)$ & \\
\hline 21 & $31(96.9)$ & $1(3.1)$ & \\
\hline 23 & $28(93.3)$ & $2(6.7)$ & \\
\hline $24-25$ & $20(95.2)$ & $1(4.8)$ & \\
\hline$\geq 27$ & $16(100)$ & $0(0)$ & \\
\hline Estimated valve $z$ score $\dagger$ & $0.99(-1.32$ to 4.24$)$ & 1.33 (0.89 to 4.46$)$ & .04 \\
\hline-2 to 0 & $13(100)$ & $0(0)$ & .45 \\
\hline 0 to +2 & $84(93.3)$ & $6(6.7)$ & \\
\hline$>2$ & $20(87)$ & $3(13)$ & \\
\hline Aortic root enlargement & & & .23 \\
\hline Yes & $28(87.5)$ & $4(12.5)$ & \\
\hline No & $90(94.7)$ & $5(5.3)$ & \\
\hline
\end{tabular}


TABLE 4. Continued

\begin{tabular}{|c|c|c|c|}
\hline Clinical characteristic & Without a reoperation & Reoperation & $P$ value \\
\hline Aortic root enlargement type & & & .22 \\
\hline Konno & $19(86.4)$ & $3(13.6)$ & \\
\hline Manougian & $4(100)$ & $0(0)$ & \\
\hline Nicks & $5(100)$ & $0(0)$ & \\
\hline Other & $0(0)$ & $1(100)$ & \\
\hline Bentall & & & .60 \\
\hline Yes & $12(100)$ & $0(0)$ & \\
\hline No & $106(92.2)$ & $9(7.8)$ & \\
\hline MVR & & & .23 \\
\hline Yes & $11(84.6)$ & $2(15.4)$ & \\
\hline No & $107(93.9)$ & $7(6.1)$ & \\
\hline MVP & & & $>.99$ \\
\hline Yes & $8(100)$ & $0(0)$ & \\
\hline No & $110(92.4)$ & $9(7.6)$ & \\
\hline Subaortic stenosis resection & & & .06 \\
\hline Yes & $4(66.7)$ & $2(33.3)$ & \\
\hline No & $114(94.2)$ & $7(5.8)$ & \\
\hline
\end{tabular}

Values are presented as median (range) or n (\%). Continuous variables were compared using the independent-samples Mann-Whitney $U$ test, and categorical variables with Fisher exact test. $B S A$, Body surface area; AS, aortic stenosis; $H L H S$, hypoplastic left heart syndrome; $S B E$, subacute bacterial endocarditis; $A R F$, acute rheumatic fever; $C P B$, cardiopulmonary bypass; $M V R$, mitral valve replacement; $M V P$, mitral valvuloplasty. *St Jude; St Jude Medical Inc, St Paul, Minn; On-X; On-X Life Technologies Inc, Austin, Tex; CarboMedics; Sorin SpA, Milan, Italy. †One case excluded from analysis due to lacking data on body surface area and calculation of estimated $z$ score.

7 years. The On-X valve has been reported to provide improved effective orifice areas and transvalvular gradients in a randomized controlled trial comparing it with the CarboMedics TopHat valve. ${ }^{25,26}$

The St Jude valve remains the gold standard mechanical prosthesis, with excellent outcomes confirmed in this series.
The St Jude valve was the first rigid bileaflet valve that was widely used after its introduction in the late $1970 \mathrm{~s}^{27}$ and has a well-described record of durability and hemodynamic performance in adults. ${ }^{28,29}$ The long-term results in patients younger than age 50 years have been quite favorable, with a low rate of valve related events with $88 \%$ survival and

TABLE 5. Cox-regression analysis of predictors of aortic valve reoperation

\begin{tabular}{|c|c|c|c|c|}
\hline \multirow[b]{2}{*}{ Variable } & \multicolumn{2}{|c|}{ Univariable analysis } & \multicolumn{2}{|c|}{ Multivariable analysis } \\
\hline & $\begin{array}{l}\text { Hazard ratio }(95 \% \\
\text { Confidence interval) }\end{array}$ & $P$ value & $\begin{array}{l}\text { Hazard ratio }(95 \% \\
\text { Confidence interval) }\end{array}$ & $P$ value \\
\hline $\operatorname{Age}(y)^{*}$ & $0.80(0.69-0.92)$ & .002 & $0.84(0.71-0.99)$ & .038 \\
\hline $1-6$ & $28.9(2.76-302.9)$ & .005 & $16.3(0.93-285)$ & .056 \\
\hline $6-12$ & $4.1(0.4-39.6)$ & .22 & $3.15(0.33-30.4)$ & .32 \\
\hline $12-18$ & $1.5(0.1-16.2)$ & .76 & $1.15(0.1-12.7)$ & .91 \\
\hline$>18$ & $\dagger$ & & $\dagger$ & \\
\hline Weight $(\mathrm{kg})$ & $0.96(0.93-0.99)$ & .04 & $1.00(0.96-1.05)$ & .94 \\
\hline Fundamental diagnosis & & .18 & & .63 \\
\hline Borderline HLHS - Shone's complex & $<0.001(0-)$ & .99 & $0(0-)$ & .98 \\
\hline Conotruncal anomalies & $2.98(0.55-16.3)$ & .21 & $2.06(0.35-12.1)$ & .42 \\
\hline Other congenital & $<0.001(0-)$ & .98 & $0(0-)$ & .97 \\
\hline Connective tissue disorder & $1.12(0.1-12.4)$ & .93 & $0.59(0.04-8.32)$ & .70 \\
\hline SBE-ARF & $16.53(1.95-140)$ & .01 & $6.03(0.57-63.6)$ & .14 \\
\hline Congenital AS & $\dagger$ & & $\dagger$ & \\
\hline Valve type & & .028 & & .70 \\
\hline St Jude & $0.11(0.02-0.55)$ & .008 & $0.44(0.07-2.99)$ & .40 \\
\hline On-X & $<0.001(0-)$ & .96 & $0(0-)$ & .96 \\
\hline CarboMedics & $\dagger$ & & $\dagger$ & \\
\hline Valve $z$ score & $2.39(0.67-8.63)$ & .18 & & \\
\hline
\end{tabular}

$\overline{H L H S}$, Hypoplastic left heart syndrome; $S B E$, subacute bacterial endocarditis; $A R F$, acute rheumatic fever; $A S$, aortic stenosis. *Age was entered as a continuous variable in 1 model, and categorical variable in separate models. †Indicator. †St Jude; St Jude Medical Inc, St Paul, Minn; On-X; On-X Life Technologies Inc, Austin, Tex; CarboMedics; Sorin SpA, Milan, Italy. 
$92 \%$ event-free survival at 19 years. ${ }^{30}$ There are few reports in the pediatric age group, but the reported results have been favorable, with most valve related bleeding episodes associated with a very prolonged INR. ${ }^{18}$ The basic St Jude bileaflet prosthesis has subsequently been modified to further improve hemodynamic performance by providing a larger internal orifice to external diameter ratio in the Hemodynamics Plus model or with a supra-annular design (Regent). In the current series, the majority of the St Jude valves used were the original design.

The On-X valve was introduced in 1996 and includes design modifications aimed at decreasing thrombogenicity. ${ }^{25,31}$ The relatively high housing around the leaflets may mitigate panus ingrowth, although implantation in a small child is rendered technically more difficult. Mid- to long-term follow-up of the initial adult patients who received this valve have been reported with favorable mortality rates and low linearized rates of thromboembolism $(0.6 \%$ and $1.8 \%$ per patient-year, respectively), bleeding $(0.4 \%$ and $0.9 \%$ per patient-year) and reoperation $(0.2 \%$ and $1.2 \%$ per patient-year). ${ }^{26}$ The Prospective Randomized On-X Valve Anticoagulation Clinical Trial randomized 375 patients undergoing AVR with the On-X valve to either standard care (goal INR, 2.0-3.0) with aspirin $81 \mathrm{mg}$ daily, or lower dose warfarin (goal INR, 1.5-2.0) and aspirin. ${ }^{32}$ Following these results, the Food and Drug Administration has approved expanded labeling of the On-X valve with these lower INR goals. These trials, included only adult patients, and further studies remain to investigate whether these results can be replicated in children and young adults with congenital heart disease. However, our experience with the On-X valve in this patient population, managed with a goal INR of 2.0 to 3.0, has shown similar results.

\section{Limitations}

This study has several limitations. First, although our study reports a large population of patients with CHD who underwent AVR, the sample size remained limited and the small number of events limited our ability to identify predictors of adverse events and perform multivariable analyses. Furthermore, selection of valve types was associated with patient characteristics (eg, the CarboMedics valves were all a $16-\mathrm{mm}$ size placed in small children, and had worse outcomes) and could confound multivariable analyses, and the differences in the numbers of patients in each valve group. Furthermore, this was a nonrandomized, retrospective study. Comparison with bioprosthetic valves was not possible, given these valves are very seldom used at our institution due to very rapid degeneration in young patients. Finally, the period of follow-up for this analysis spanned nearly a decade and a half, from 2000 to 2014. It is possible that some aspects of surgical technique changed during that period that are not fully accounted for in our comparisons of time to AVR by valve type.

\section{CONCLUSIONS}

Mechanical AVR in patients with CHD has acceptable midterm outcomes, despite younger patients with smaller valves undergoing more reoperations. The newer generation On-X valves perform at least as well as St Jude valves and despite the necessary anticoagulation, there were very few bleeding or thromboembolic complications in this patient population.

\section{Conflict of Interest Statement}

Authors have nothing to disclose with regard to commercial support.

\section{References}

1. Bacha EA, McElhinney DB, Guleserian KJ, Colan SD, Jonas RA, del Nido PJ, et al. Surgical aortic valvuloplasty in children and adolescents with aortic regurgitation: acute and intermediate effects on aortic valve function and left ventricular dimensions. J Thorac Cardiovasc Surg. 2008;135:552-9.

2. Myers PO, Bautista-Hernandez V, del Nido PJ, Marx GR, Mayer JE, Pigula FA, et al. Surgical repair of truncal valve regurgitation. Eur J Cardiothorac Surg. 2013;44:813-20.

3. Myers PO, Tissot C, Christenson JT, Cikirikcioglu M, Aggoun Y, Kalangos A. Aortic valve repair by cusp extension for rheumatic aortic insufficiency in children: long-term results and impact of extension material. J Thorac Cardiovasc Surg. 2010;140:836-44.

4. d'Udekem Y, Siddiqui J, Seaman CS, Konstantinov IE, Galati JC, Cheung MM, et al. Long-term results of a strategy of aortic valve repair in the pediatric population. J Thorac Cardiovasc Surg. 2013;145:461-7; discussion 467-9.

5. Hraska V, Photiadis J, Arenz C. Open valvotomy for aortic valve stenosis in newborns and infants. Multimed Man Cardiothorac Surg. 2007;2007:mmcts 2006.002311 .

6. Woods RK, Pasquali SK, Jacobs ML, Austin EH, Jacobs JP, Krolikowski M, et al. Aortic valve replacement in neonates and infants: an analysis of the Society of Thoracic Surgeons congenital heart surgery database. J Thorac Cardiovasc Surg. 2012;144:1084-9.

7. Alsoufi B, Al-Halees Z, Fadel B, Al-Wesabi A, Al-Ahmadi M, Joufan M, et al. Simultaneous aortic and mitral valve replacement in children: time-related outcomes and risk factors. J Heart Valve Dis. 2010;19:341-8.

8. Nishimura RA, Otto CM, Bonow RO, Carabello BA, Erwin JP III, Guyton RA, et al. 2014 AHA/ACC guideline for the management of patients with valvular heart disease: a report of the American College of Cardiology/American Heart Association task force on practice guidelines. J Thorac Cardiovasc Surg. 2014; 148:e1-132.

9. Myers PO, del Nido PJ, McElhinney DB, Khalpey Z, Lock JE, Baird CW Annulus upsizing for mitral valve re-replacement in children. J Thorac Cardiovasc Surg. 2013;146:347-51.

10. Henaine R, Roubertie F, Vergnat M, Ninet J. Valve replacement in children: a challenge for a whole life. Arch Cardiovasc Dis. 2012;105:517-28.

11. Karamlou T, Jang K, Williams WG, Caldarone CA, Van Arsdell G, Coles JG, et al. Outcomes and associated risk factors for aortic valve replacement in 160 children: a competing-risks analysis. Circulation. 2005;112:3462-9.

12. Turrentine MW, Ruzmetov M, Vijay P, Bills RG, Brown JW. Biological versus mechanical aortic valve replacement in children. Ann Thorac Surg. 2001;71: S356-60.

13. d'Udekem Y. Aortic valve surgery in children. Heart. 2011;97:1182-9.

14. Saleeb SF, Newburger JW, Geva T, Baird CW, Gauvreau K, Padera RF, et al Accelerated degeneration of a bovine pericardial bioprosthetic aortic valve in children and young adults. Circulation. 2014;130:51-60.

15. Samir K, Riberi A, Kreitmann B, Metras D. The Ross operation as an ideal choice for aortic valve replacement in patients with congenital disease. J Thorac Cardiovasc Surg. 2003;125:738-9.

16. Pasquali SK, Shera D, Wernovsky G, Cohen MS, Tabbutt S, Nicolson S, et al. Midterm outcomes and predictors of reintervention after the Ross procedure in infants, children, and young adults. J Thorac Cardiovasc Surg. 2007;133:893-9.

17. Vosa C, Renzulli A, Lombardi PF, Damiani G. Mechanical valve replacemen under 12 years of age: 15 years of experience. J Heart Valve Dis. 1995;4:279-83. 
18. Cabalka AK, Emery RW, Petersen RJ, Helseth HK, Jakkula M, Arom KV, et al. Long-term follow-up of the St. Jude medical prosthesis in pediatric patients. Ann Thorac Surg. 1995;60:S618-23.

19. Manouguian S, Seybold-Epting W. Patch enlargement of the aortic valve ring by extending the aortic incision into the anterior mitral leaflet. New operative technique. J Thorac Cardiovasc Surg. 1979;78:402-12.

20. Konno S, Imai Y, Iida Y, Nakajima M, Tatsuno K. A new method for prosthetic valve replacement in congenital aortic stenosis associated with hypoplasia of the aortic valve ring. J Thorac Cardiovasc Surg. 1975;70:909-17.

21. Nicks R, Cartmill T, Bernstein L. Hypoplasia of the aortic root. The problem of aortic valve replacement. Thorax. 1970;25:339-46.

22. Bortolotti U, Celiento M, Milano AD. Enlargement of the aortic annulus during aortic valve replacement: a review. J Heart Valve Dis. 2014;23:31-9.

23. Cappelleri JC, Fiore LD, Brophy MT, Deykin D, Lau J. Efficacy and safety of combined anticoagulant and antiplatelet therapy versus anticoagulant monotherapy after mechanical heart-valve replacement: a metaanalysis. Am Heart J. 1995;130:547-52.

24. Bradley SM. Aortic valve insufficiency in the teenager and young adult: the role of prosthetic valve replacement. World Jr Pediatr Congenit Heart Surg. 2013;4: 397-402.

25. Halkos ME, Puskas JD. Are all bileaflet mechanical valves equal? Curr Opin Cardiol. 2009;24:136-41.

26. Chambers J, Roxburgh J, Blauth C, O'Riordan J, Hodson F, Rimington H. A randomized comparison of the MCRI On-X and CarboMedics Top Hat bileaflet mechanical replacement aortic valves: early postoperative hemodynamic function and clinical events. J Thorac Cardiovasc Surg. 2005; 130:759-64.
27. Nicoloff DM, Emery RW, Arom KV, Northrup WF III, Jorgensen CR, Wang Y, et al. Clinical and hemodynamic results with the St. Jude Medical cardiac valve prosthesis. A three-year experience. J Thorac Cardiovasc Surg. 1981;82: 674-83.

28. Emery RW, Krogh CC, Arom KV, Emery AM, Benyo-Albrecht K, Joyce LD, et al. The St. Jude Medical cardiac valve prosthesis: a 25-year experience with single valve replacement. Ann Thorac Surg. 2005;79:776-82; discussion 782773 .

29. Ikonomidis JS, Kratz JM, Crumbley AJ III, Stroud MR, Bradley SM, Sade RM, et al. Twenty-year experience with the St Jude Medical mechanical valve prosthesis. J Thorac Cardiovasc Surg. 2003;126:2022-31.

30. Emery RW, Erickson CA, Arom KV, Northrup WF III, Kersten TE, Von Rueden TJ, et al. Replacement of the aortic valve in patients under 50 years of age: long-term follow-up of the St. Jude Medical prosthesis. Ann Thorac Surg. 2003;75:1815-9.

31. Hwang NH, Reul H, Reinhard P. In vitro evaluation of the long-body On-X bileaflet heart valve. J Heart Vlave Dis. 1998;7:561-8.

32. Puskas J, Gerdisch M, Nichols D, Quinn R, Anderson C, Rhenman B, et al. Reduced anticoagulation after mechanical aortic valve replacement: interim results from the prospective randomized on- $\mathrm{X}$ valve anticoagulation clinical trial randomized food and drug administration investigational device exemption trial. J Thorac Cardiovasc Surg. 2014;147:1202-10.

Key Words: aortic valve replacement, pediatric cardiac surgery, mechanical valve, aortic valve 